\title{
Chemotherapy-induced modification of microRNA expression in esophageal cancer
}

\author{
RICHARD HUMMEL ${ }^{1,4}$, TINGTING WANG ${ }^{1}$, DAVID I. WATSON ${ }^{1}$, MICHAEL Z. MICHAEL $^{2}$, \\ MARK VAN DER HOEK ${ }^{3}$, JOERG HAIER ${ }^{5}$ and DAMIAN J. HUSSEY ${ }^{1}$ \\ Departments of ${ }^{1}$ Surgery, and ${ }^{2}$ Gastroenterology and Hepatology, Flinders University, 5042 Bedford Park SA; \\ ${ }^{3}$ Adelaide Microarray Centre, IMVS Main Building, 5000 Adelaide SA, Australia; ${ }^{4}$ Department of General and \\ Visceral Surgery and ${ }^{5}$ Comprehensive Cancer Centre, University of Muenster, 48149 Muenster, Germany
}

Received May 6, 2011; Accepted June 3, 2011

DOI: $10.3892 /$ or.2011.1381

\begin{abstract}
Neoadjuvant chemotherapy is often used in the treatment of advanced esophageal cancer. In this study, we determined the impact of chemotherapy on microRNA (miRNA) expression in esophageal cancer cells, and whether identified changes might have biological relevance. Two esophageal carcinoma cell lines (one adenocarcinoma and one squamous cell carcinoma) were treated with cisplatin or 5-fluorouracil for 24 or $72 \mathrm{~h}$. RNA was extracted from cells following 24-h treatment, and used for microarray studies. Promising miRNA candidates were selected for RT-PCR validation. Target prediction using TargetScan, combined with bioinformatic analysis (Ingenuity Pathway Analysis, IPA), was performed to evaluate the implications of the altered miRNA expression. Thirteen miRNAs (miR-199a-5p, miR-302f, miR-320a, miR-342-3p, miR-425, miR-455-3p, miR-486-3p, miR-519c-5p, miR-548d-5p, miR-617, miR-758, miR-766, miR-1286) were deregulated after 24- and/or 72-h treatment in both cell lines, and most miRNAs presented similar expression changes after short- or long-term exposure. IPA revealed that the major networks which incorporate the predicted targets, include functions such as 'Cell death', 'Cell cycle', 'Cellular growth and proliferation', 'DNA replication, recombination, and repair' and 'Drug metabolism'. Cisplatin or 5-fluorouracil alter miRNA expression in esophageal cancer cells. IPA suggests that these miRNAs may target molecular pathways involved in cell survival after chemotherapy.
\end{abstract}

\section{Introduction}

The prognosis for esophageal cancer remains poor, and the majority of patients present with advanced stage disease.

Correspondence to: Dr Richard Hummel, Department of General and Visceral Surgery, University of Muenster, 48149 Muenster, Germany

E-mail: richard.hummel@ukmuenster.de

Key words: microRNA, chemotherapy, cisplatin, 5-fluorouracil, esophageal cancer
Neoadjuvant chemoradiotherapy is used as a strategy to improve post-surgical treatment outcomes, and response to treatment has been reported to be an independent prognostic factor following esophagectomy (1-5). Currently, however, some patients respond well to chemotherapy, and some do not. Identifying patients who may or may not benefit from neoadjuvant chemotherapy may help better tailor clinical treatments.

Molecular markers, such as microRNAs (miRNAs, miRs), might provide a promising new approach in this context. MicroRNAs are small non-coding RNA molecules which regulate gene expression. Changes in miRNA expression have been found in various malignancies after exposure to cytotoxic stimuli such as radiotherapy and chemotherapy (6). In our current study we determined whether exposure to cisplatin and 5-fluorouracil (5-FU), the two most commonly used agents for the treatment of esophageal cancer, leads to alterations in the miRNA expression in esophageal adenocarcinoma (EAC) and squamous cell carcinoma (SCC) cell lines, as well as the biological relevance of any identified changes.

\section{Materials and methods}

EAC and SCC cell lines were treated with cisplatin or 5-FU for $24 \mathrm{~h}$ (short-term) or $72 \mathrm{~h}$ (long-term), and miRNA expression was analyzed via microarray and RT-PCR. Target prediction and bioinformatic analysis was then used to elucidate possible effects of the observed alterations in miRNA expression.

Cell lines and cell culture. The human squamous cell carcinoma cell line KYSE410 (obtained from the Molecular Biology Laboratory, University Hospital Muenster, Germany), and the human adenocarcinoma cell line OE19 (obtained from the Department of Surgery, Flinders University Adelaide, Australia) were cultured using RPMI-1640 medium (\#11875) or DMEM high glucose 1X medium (\#11995) respectively, supplemented with 10\% fetal bovine serum (\#26140), 1\% penicillin-streptomycin (all from Gibco ${ }^{\circledR}$ Invitrogen, \#15140; 10,000 units of penicillin and $10,000 \mu \mathrm{g}$ of streptomycin per $1 \mathrm{ml}$ ) and 2\% Normocin ${ }^{\mathrm{TM}}$ (InvivoGen, San Diego, CA, USA, Catalog \# ant-nr-1; $50 \mathrm{mg} / \mathrm{ml}$ ) in a humidified atmosphere containing $5 \% \mathrm{CO}_{2}$ at $37^{\circ} \mathrm{C}$. For drug sensitivity assays, phenol 
Table I. miRNAs assessed via RT-PCR in the respective experimental groups.

Experimental group miRNAs

SCC

Treated with cisplatin $\quad$ hsa-miR-16, hsa-miR-17, hsa-miR-18b, hsa-miR-28-3p, hsa-miR-106a, hsa-miR-320a, hsa-miR-342-3p, hsa-miR-423-5p, hsa-miR-425, hsa-miR-514, hsa-miR-1197, hsa-miR-1304

Treated with 5-fluorouracil hsa-miR-199a-5p, hsa-miR-423-5p, hsa-miR-486-3p, hsa-miR-597, hsa-miR-617, hsa-miR-758, hsa-miR-766, hsa-miR-876-3p, hsa-miR-1197, hsa-miR-1286, hsa-miR-1304

EAC

Treated with cisplatin

hsa-miR-27b, hsa-miR-146b-3p, hsa-miR-337-5p, hsa-miR-411, hsa-miR-455-3p, hsa-miR-519c-3p, hsa-miR-543, hsa-miR-548d-5p, has- miR-581, hsa-miR-642, hsa-miR-650, hsa-miR-1288

Treated with 5-fluorouracil hsa-miR-146b-3p, hsa-miR-302f, hsa-miR-361-3p, hsa- miR-376c, hsa-miR-432, hsa-miR-486-3p, hsa-miR-519c-5p, hsa- miR-581, hsa-miR-631, hsa-miR-642, hsa-miR-643, hsa-miR-802

red-free (RPMI-1640 medium, \#11835; DMEM/F12 1:1: Gibco Invitrogen, \#11039) containing the same supplements was used.

Drug treatment. Cells were seeded into 6-well plates $\left(9.5 \times 10^{4}\right.$ and $2 \times 10^{5}$ viable cells/well respectively, for KYSE410 and OE19) and allowed to attach. After reaching 30-60\% confluency (for short-term experiments) or 10-20\% confluency (for long-term experiments), fresh medium containing cisplatin or 5-FU was prepared and added to the corresponding cells. The concentrations of drugs used in this context represented the approximate median lethal doses (LD50) after 72-h exposure in the respective cell lines (KYSE410, $5 \mu \mathrm{M}$ cisplatin, $5 \mu \mathrm{M}$ 5-FU; OE19, $20 \mu \mathrm{M}$ cisplatin, $100 \mu \mathrm{M}$ 5-FU; determined in previous experiments, data not shown). After 24-h (shortterm experiments) or 72-h exposure (long-term experiments), cells were lysed in TRIzol ${ }^{\circledR}$ (Invitrogen Life Technologies, $\mathrm{NY}$, USA) and stored at $-20^{\circ} \mathrm{C}$ for later RNA processing. All experiments were performed in 3 independent replicates.

RNA extraction and preparation. Extraction of total RNA from the lysate was performed according to the manufacturer's protocol. The concentration of RNA was quantified by UV spectrophotometry (NanoDrop ${ }^{\circledR}$ ND-8000 Spectrophotometer, Thermo Fisher Scientific, Wilmington, USA). RNA quality was determined by electrophoresis through a $1 \%$ agarose gel. All RNA samples were confirmed to be undegraded by visualization of the distinct $28 \mathrm{~S}$ and $18 \mathrm{~S}$ rRNA species. The final RNA solution was stored at $-20^{\circ} \mathrm{C}$.

DNase-pretreatment. In order to remove contaminating DNA from RNA preparations, and to subsequently remove the DNase and divalent cations from the sample, all samples were treated with Ambion ${ }^{\circledR}$ TURBO DNA-free ${ }^{\mathrm{TM}}$ (Applied Biosystems, Foster City, CA, USA, cat\# AM1907). Briefly, $500 \mathrm{ng}$ of RNA (dissolved in 8- $\mu 1$ nuclease-free water) were incubated with $1 \mu \mathrm{l} 10 \mathrm{X}$ TURBO DNase Buffer and $1 \mu \mathrm{l}$ rDNase I for $30 \mathrm{~min}$ at $37^{\circ} \mathrm{C}$ in a thermocycler (Eppendorf Mastercycler, Eppendorf, North Ryde, NSW, Australia). Then, samples were incubated with $1 \mu \mathrm{l}$ DNase Inactivation reagent for $5 \mathrm{~min}$ at room temperature, and centrifuged at $10,000 \mathrm{~g}$ for $5 \mathrm{~min}$ at $4^{\circ} \mathrm{C}$. DNase treated RNA was finally incubated for $10 \mathrm{~min}$ at $75^{\circ} \mathrm{C}$, and stored on ice for further processing.
miRNA selection. We performed an initial microarray study (Affymetrix GeneChip miRNA Array which contained 848 miRNAs representing Sanger miRBase v11) on the samples exposed for $24 \mathrm{~h}$ to cisplatin or 5-FU. We then compared these preliminary data with published literature on miRNAs associated with chemotherapy in different tumour types, and selected a number of miRNAs that represent valid candidates in the context of chemotherapy-induced alterations of miRNA expression. We then filtered this list to select miRNAs which had predicted targets with a Total Context Score of $<-0.5$ in TargetScan (7). An overview of the miRNAs selected for RT-PCR validation in the respective experimental groups is shown in Table I.

Reverse transcription and RT-PCR using Qiagen miScript $P C R$ system. The miScript PCR system (Qiagen, Doncaster, Australia) was used to validate all miRNAs in the short-term and long-term experiments, except for miR-106a for which the TaqMan ${ }^{\circledR}$ miRNA assay (hsa-miR-106a: ID 002169, RNU44: ID 001094) from Applied Biosystems was used. Qiagen miScript assays were undertaken according to the manufacturer's instructions. For each sample, $500 \mathrm{ng}$ of DNase treated RNA was used for reverse transcription into cDNA. Following the manufacturer's protocol, we utilized $4 \mu 1$ miScript 5X RT Buffer, $1 \mu \mathrm{l}$ Reverse Transcriptase and $5 \mu \mathrm{l}$ nuclease-free water. Incubation of reagents was performed in a thermocycler (protocol: $60 \mathrm{~min}$ at $37^{\circ} \mathrm{C}, 5 \mathrm{~min}$ at $95^{\circ} \mathrm{C}$, then a hold at $4^{\circ} \mathrm{C}$ ). For real-time PCR, $5 \mu \mathrm{l}$ of cDNA was mixed with $10 \mu \mathrm{l}$ 2X QuantiTect SYBR, $2 \mu 1$ 10X miScript Universal Primer, $2 \mu \mathrm{l}$ gene specific $10 \mathrm{X}$ miScript Primer Assay, and $1 \mu \mathrm{l}$ nuclease-free water. All samples were assayed in triplicate reactions using a Rotorgene 6000 thermocycler (Corbett Life Science, Sydney, NSW, Australia). Quantitative analysis was performed using Q-Gene software. miRNA expression data were normalized to the expression levels of RNU44, which displayed comparable expression across the different groups (data not shown).

Statistical analysis. Gene expression data for miRNAs were expressed as the means of normalized expression with standard deviation. Data were assessed for statistical significance using the Student's t-test for equal and unequal variances, 
Table II. Fold changes in gene expression after short-term (24 h) or long-term (72 h) exposure to cisplatin or 5-fluorouracil.

\begin{tabular}{|c|c|c|c|c|c|c|}
\hline & \multicolumn{3}{|c|}{ Cisplatin } & \multicolumn{3}{|c|}{ 5-Fluorouracil } \\
\hline & miRNA & Fold-change (short/long) & p-value & miRNA & Fold-change (short/long) & $\mathrm{p}$-value \\
\hline \multirow[t]{11}{*}{ SCC } & $\operatorname{miR}-18 b$ & $1.7(\uparrow) / 1.4(\downarrow)$ & $0.225 / 0.421$ & miR-1304 & $1.1(\uparrow) /^{\mathrm{a}}$ & $0.081 /{ }^{\mathrm{a}}$ \\
\hline & miR-106a & $1.1(\uparrow) / 1.1(\downarrow)$ & $0.510 / 0.403$ & miR-617 & $1.7(\uparrow) / 2.3(\uparrow)$ & $0.007 / 0.016$ \\
\hline & miR-1304 & $1.0(\downarrow) /)^{\mathrm{a}}$ & $0.958 /^{\mathrm{a}}$ & miR-199a-5p & $1.8(\uparrow) / 2.0(\uparrow)$ & $0.009 / 0.019$ \\
\hline & miR-423-5p & $1.1(\uparrow) / 1.2(\uparrow)$ & $0.182 / 0.159$ & miR-758 & $1.8(\uparrow) / 2.2(\uparrow)$ & $0.007 / 0.025$ \\
\hline & miR-342-3p & $1.2(\uparrow) / 1.6(\uparrow)$ & $0.075 / \mathbf{0 . 0 1 5}$ & miR-766 & $1.4(\uparrow) / 2.1(\uparrow)$ & $0.023 / 0.028$ \\
\hline & $\operatorname{miR}-28-3 p$ & $1.0(\downarrow) / 1.2(\downarrow)$ & $0.769 / 0.344$ & miR-876-3p & $1.2(\uparrow) / 1.2(\downarrow)$ & $0.159 / 0.497$ \\
\hline & miR-425 & $1.4(\uparrow) / 1.6(\uparrow)$ & $0.000 / 0.020$ & $\operatorname{miR}-486-3 p$ & $2.0(\uparrow) / 1.5(\uparrow)$ & $0.004 / 0.100$ \\
\hline & miR-17 & $1.6(\uparrow) / 1.3(\downarrow)$ & $0.120 / 0.424$ & $\operatorname{miR}-423-5 p$ & $1.1(\uparrow) / 1.2(\uparrow)$ & $0.174 / 0.171$ \\
\hline & miR-514 & $1.1(\uparrow) / 1.2(\uparrow)$ & $0.614 / 0.635$ & miR-1286 & $1.7(\uparrow) / 2.4(\uparrow)$ & 0.001/0.007 \\
\hline & miR-16 & $1.4(\uparrow) / 1.1(\uparrow)$ & $0.074 / 0.206$ & & & \\
\hline & miR-320a & $1.2(\uparrow) / 1.3(\uparrow)$ & $\mathbf{0 . 0 3 2} / 0.101$ & & & \\
\hline \multirow[t]{7}{*}{ EAC } & miR-548d-5p & $1.5(\downarrow) /^{\mathrm{a}}$ & $0.044 /^{\mathrm{a}}$ & miR-432 & $1.0(\uparrow) / 2.0(\uparrow)$ & $0.936 / 0.068$ \\
\hline & miR-642 & $1.0(\downarrow) / 1.1(\uparrow)$ & $0.868 / 0.062$ & $\operatorname{miR}-376 c$ & $1.6(\uparrow) /^{\mathrm{a}}$ & $0.131 /^{\mathrm{a}}$ \\
\hline & $\operatorname{miR}-543$ & $1.5(\downarrow) / 1.5(\downarrow)$ & $0.087 / 0.349$ & miR-519c-5p & $1.3(\uparrow) / 1.4(\uparrow)$ & $0.005 / 0.021$ \\
\hline & miR-455-3p & $1.7(\downarrow) / 2.0(\downarrow)$ & $0.018 / 0.001$ & $\operatorname{miR}-486-3 p$ & $1.0(\downarrow) / 1.3(\uparrow)$ & $0.509 / 0.249$ \\
\hline & $\operatorname{miR}-27 b$ & $1.3(\downarrow) / 1.1(\downarrow)$ & $0.252 / 0.465$ & miR-361-3p & $1.0(\uparrow) / 1.3(\uparrow)$ & 0.8370 .051 \\
\hline & $\operatorname{miR}-411$ & $1.3(\downarrow) / 1.1(\downarrow)$ & $0.292 / 0.794$ & miR-642 & $1.0(\downarrow) / 1.1(\uparrow)$ & $0.812 / 0.247$ \\
\hline & & & & miR-302f & $1.3(\uparrow) / 1.9(\uparrow)$ & $0.023 / 0.035$ \\
\hline
\end{tabular}

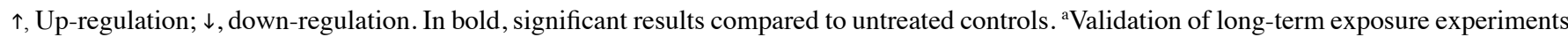
not performed.

as appropriate, based on the Levene's test for homogeneity of variances. $\mathrm{P}<0.05$ was considered to be statistically significant. All analyses were performed using SPSS 17.0 for Windows (SPSS, Chicago, IL).

miRNA target prediction and pathway analysis. Target prediction using TargetScan (http://www.targetscan.org) and pathway prediction using Ingenuity Pathway Analysis (IPA) (Ingenuity ${ }^{\circledR}$ Systems; www.ingenuity.com) were combined to elucidate possible implications of altered miRNA expression. Predicted targets used in this analysis were required to present a total context score of $<-0.5$ in TargetScan. The total context score for a specific site is the sum of the contribution of these four features: site-type, $3^{\prime}$ pairing, local $\mathrm{AU}$ content and position, which represents a parameter of site accessibility. Ingenuity Pathway Analysis parameters were set to assess a knowledge base derived from direct and indirect associations between genes in human experiments and cell lines. In the Ingenuity Pathway Analysis, genes are grouped according to function and are allocated to top associated networks and cellular functions. Ingenuity Pathway Analysis uses a right tailed Fisher's exact test to assign p-values to each grouping, testing each result against a result from random groups of input predicted genes. Networks and cellular functions are ranked according to their score with the highest scoring networks representing the greatest statistical significance. In the context of cellular functions, we focused our attention to those functions which might represent an important step in the cellular response to cytotoxic stimulus. As cells might activate various processes, including overcoming the cytotoxic stress (for example the activation of drug metabolizing enzymes or drug efflux pumps) or initiating apoptosis and cell death, we selected the following functions from the provided IPA results, 'Cellular growth and proliferation', 'Cell cycle', 'Cell death', 'DNA replication, recombination and repair' and 'Drug metabolism'.

\section{Results}

The comparison of miRNA expression between the short-term or long-term treatment of cell lines and the untreated controls revealed an explicit impact of chemotherapy on the miRNA expression profile in both histological subtypes.

Altered miRNA expression after chemotherapy. Table II presents an overview of PCR validation results including the fold-change in gene expression after treatment, compared to sham-treated controls, and associated p-values. In total, 33 of the selected miRNAs were expressed at detectable levels in the esophageal cancer cell lines used in this study, and the expression of 13 of these miRNAs was significantly altered after exposure to chemotherapy in at least one cancer cell line. Changes in the expression after chemotherapy approached significance in another 5 miRNAs (miR-642, miR-543, miR-361-3p, miR-432, miR-1304; p-value between 0.051 and 0.087). Most of the significantly deregulated miRNAs showed an induction in expression after chemotherapeutic treatment, compared to untreated controls. In SCC, nine miRNAs 

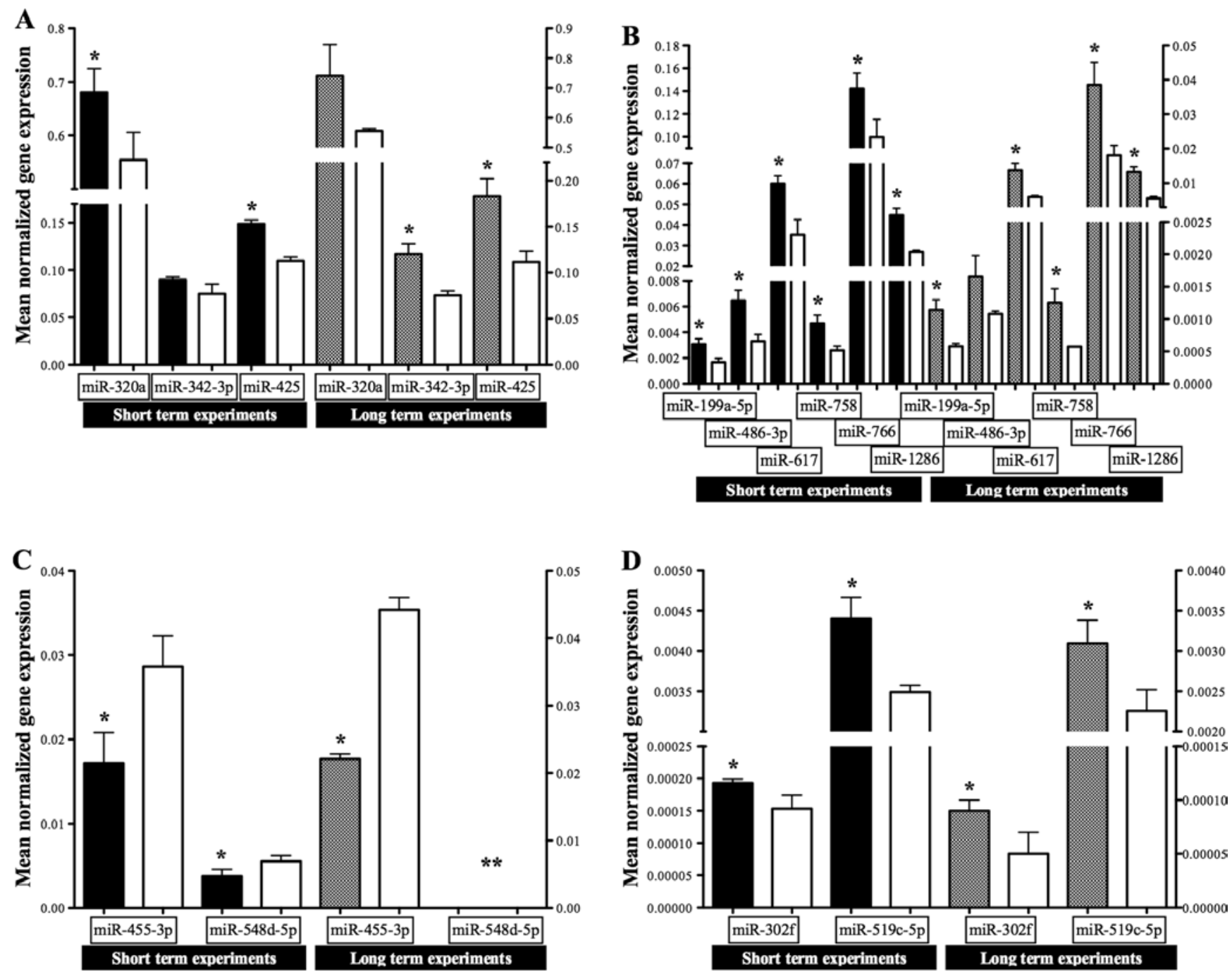

Figure 1. Mean normalized gene expression (with standard deviation) of differentially expressed miRNAs after treatment with cisplatin (A) or 5-fluorouracil (B) in SCC or with cisplatin (C) or 5-fluorouracil (D) in EAC cell lines of the esophagus. Short-term experiment, treatment for $24 \mathrm{~h}$, attached to the left y-axis; long-term experiments, treatment for $72 \mathrm{~h}$, attached to the right y-axis. Black and grey bars, miRNA expression in cells treated short-term or long-term with chemotherapeutic drug. White bars, miRNA expression in not-treated controls. "Significant vs. respective control. "*miR-548d-5p, no data for long-term exposure available.

(miR-199a-5p, miR-320a, miR-342-3p, miR-425, miR-486-3p, miR-617, miR-758, miR-766 and miR-1286) were more highly expressed after chemotherapy treatment with either drug, and in EAC, two miRNAs (miR-302f and miR-519c-5p) presented an increased expression after 5-FU treatment. Only two miRNAs (miR-455-3p and miR-548d-5p) showed a decreased expression after cisplatin treatment in EAC. Fig. 1 summarizes the mean normalized expression of the differentially expressed miRNAs.

The expression of 11 of the selected miRNAs (miR146b-3p, miR-337-5p, miR-519c-3p, miR-581, miR-597, miR-631, miR-643, miR-650, miR-802, miR-1197, miR-1288) was extremely low in the esophageal cancer cell lines used (take-off of amplified product $>30$ ), and analysis of the PCR products indicated a lack of specificity in amplification. These miRNAs were therefore excluded from further statistical analysis.

Cisplatin vs. 5-FU. Both chemotherapy agents impacted the miRNA expression. 5-FU treatment was followed by an increase in the levels of eight miRNAs, compared to untreated controls. Cisplatin treatment was followed by an increase in the levels of three miRNAs, and a reduction in the expression of two miRNAs.

Short-term vs. long-term treatment. In most cases, similar deregulation of a particular miRNA was found after long-term exposure (treatment of cells over $72 \mathrm{~h}$ ) compared to short-term exposure experiments (treatment of cells over $24 \mathrm{~h}$ ) with the same chemotherapeutic agent.

miRNA target prediction and pathway analysis

TargetScan analysis. The criteria used for TargetScan prediction provided a number of putative targets for each miRNA for further analysis. Lists of predicted miRNA targets from the same experiment were combined into four groups (A-D) in preparation for IPA network analysis [A, SCC treated with cisplatin ( $\mathrm{n}=93$ ); B, SCC treated with 5-FU ( $\mathrm{n}=112)$; C, EAC treated with cisplatin $(\mathrm{n}=151)$; D, EAC treated with 5 -FU $(\mathrm{n}=32)]$. 
Table III. Overview of the 'Top \#1 Networks' for the respective experiments provided by IPA analysis including the significance score.

\begin{tabular}{|c|c|c|}
\hline Experiment & Top \#1 Network & Score \\
\hline \multicolumn{3}{|l|}{ SCC } \\
\hline Treated with cisplatin & Cellular movement, Cellular growth and proliferation, Cellular development & 15 \\
\hline Treated with 5-fluorouracil & Immunological disease, Cell death, Respiratory disease & 13 \\
\hline \multicolumn{3}{|l|}{ EAC } \\
\hline Treated with cisplatin & Cell cycle, Cell death, Connective tissue development and function & 18 \\
\hline Treated with 5-fluorouracil & Cell cycle, DNA replication, recombination, and repair, Cell death & 9 \\
\hline
\end{tabular}

Table IV. Selected 'Molecular and cellular functions' provided by IPA analysis.

\begin{tabular}{|c|c|c|c|}
\hline Experiment & Molecular and cellular functions & p-value & No. of genes \\
\hline \multicolumn{4}{|l|}{$\mathrm{SCC}$} \\
\hline \multirow[t]{5}{*}{ Treated with cisplatin } & Cellular growth and proliferation & $1.75 \mathrm{E}-04-4.99 \mathrm{E}-02$ & 8 \\
\hline & Cell cycle & 5.31E-04-4.99E-02 & 8 \\
\hline & Cell death & 7.06E-04-4.50E-02 & 10 \\
\hline & DNA replication, recombination and repair & $1.911 \mathrm{E}-02-4.99 \mathrm{E}-02$ & 6 \\
\hline & Drug metabolism & $3.02 \mathrm{E}-02-4.50 \mathrm{E}-02$ & 1 \\
\hline \multirow[t]{5}{*}{ Treated with 5-fluorouracil } & Cellular growth and proliferation & $5.53 \mathrm{E}-3-2.74 \mathrm{E}-02$ & 3 \\
\hline & DNA replication, recombination and repair & $5.53 \mathrm{E}-3-3.81 \mathrm{E}-02$ & 2 \\
\hline & Cell death & $1.10 \mathrm{E}-02-4.87 \mathrm{E}-02$ & 2 \\
\hline & Cell cycle & $1.65 \mathrm{E}-02-1.65 \mathrm{E}-02$ & 1 \\
\hline & Drug metabolism & 2.19E-02-2.19E-02 & 1 \\
\hline \multicolumn{4}{|l|}{ EAC } \\
\hline \multirow[t]{5}{*}{ Treated with cisplatin } & Cell death & $6.98 \mathrm{E}-03-3.10 \mathrm{E}-02$ & 12 \\
\hline & Cell cycle & 8.72E-03-3.44E-02 & 3 \\
\hline & Drug metabolism & 8.72E-03-4.29E-02 & 2 \\
\hline & DNA replication, recombination and repair & $1.05 \mathrm{E}-02-3.44 \mathrm{E}-02$ & 3 \\
\hline & Cellular growth and proliferation & 3.44E-02-4.75E-02 & 3 \\
\hline \multirow[t]{4}{*}{ Treated with 5-fluorouracil } & Cell cycle & 4.11E-03-4.82E-02 & 4 \\
\hline & Cell death & 4.11E-03-1.84E-02 & 4 \\
\hline & DNA replication, recombination and repair & 3.44E-02-3.44E-02 & 1 \\
\hline & Cellular growth and proliferation & 4.43E-02-4.43E-02 & 1 \\
\hline
\end{tabular}

Including p-value and number of genes in the respective pathway (= predicted targets of the differentially expressed miRNAs in the respective experiment; obtained from TargetScan analysis, for details see Materials and methods). In bold and italics, listed among the Top 5 Bio Functions in the section 'Molecular and cellular functions'.

IPA network analysis. Table III presents an overview of the IPA network analysis. In all experiments, the most significant network included functions that are relevant to cell survival and maintenance of cellular growth and proliferation. These networks presented the highest score of all networks provided by the IPA ( $p$-value-based score which represents the likelihood that predicted targets within a network are found therein by chance).

IPA function analysis. A more detailed analysis of the data focusing on 'Molecular and cellular functions' is shown in Table IV. In all experiments, functions such as 'Cell death', 'Cell cycle', 'Cellular growth and proliferation', 'DNA repli- cation, recombination, and repair' and 'Drug metabolism' were identified with a high likelihood to differ significantly from the results of random groups of input genes. In 3 out of 4 experiments, these functions showed even the greatest statistical significance and were listed amongst the Top 5 Bio Functions in the section 'Molecular and cellular functions'.

\section{Discussion}

There is increasing evidence that chemotherapy treatment with various anticancer drugs such as curcumin (a naturally occurring flavinoid), gemcitabine, 5-FU, capecitabine 
or fludarabine affects miRNA expression in a number of cancers including lung adenocarcinoma, chronic lymphocytic leukemia, pancreatic and colorectal cancer (8-14). Our current study presents the first evidence that chemotherapy affects miRNA expression in esophageal cancer cells. Cisplatin treatment was followed by up-regulation of miR-342-3p, miR-425 and miR-320a in SCC and down-regulation of miR-548d-5p and miR-455-3p in EAC. 5-FU treatment was followed by increased expression of miR-617, miR-199a-5p, miR-758, miR-766, miR-486-3p and miR-1286 in SCC and of miR519c-5p and miR-302f in EAC. In addition, similar changes in miRNA expression were identified after short- or long-term exposure to both drugs, possibly implicating these miRNAs in response to chemotherapy. Analysis of predicted targets of these miRNAs highlighted molecular networks which include functions such as 'Cell death', 'Cell cycle', 'Cellular growth and proliferation', 'DNA replication, recombination, and repair' and 'Drug metabolism', and this suggests that the identified changes in miRNA expression are consistent with a biological effect in the cells responding to the cytotoxic agents.

Deregulation or stable expression has been reported for several of the identified miRNAs, including miR-342-3p, miR-425 or miR-455-3p, in inflammatory breast cancer, multiple myeloma, acute promyelocytic leukemia, glioblastoma, colorectal cancer, malignant mesothelioma or hepatocellular carcinoma, and they seem to play a role in cancer development by affecting proliferation, cell cycle control, migration, angiogenesis, differentiation, invasion and hypoxia (miR-199a-5p) (15-23). More interestingly, some of the identified miRNAs or members of their families (namely miR-342, miR-758, miR$519 \mathrm{c}$ and miR-455-3p) were found to be deregulated in drug resistant cancer cell lines, and ectopic modulation of miR-519c and miR-455-3p expression has been shown to impact on the sensitivity to mitoxantrone and temozolomide treatment respectively. In this context, ABCG2, LTBR (a proapoptotic gene), EI24 (a p53-target gene) and SMAD2 have been identified as putative targets for these two miRNAs (24-27).

Some limitations of our current study need to be recognized when interpreting our results. The most important limitation is the restriction to two esophageal cancer cell lines (OE19 and KYSE410 respectively), rather than a broader range of cell lines or in vivo studies. When we designed our study we aimed to test the hypothesis that chemotherapy affects miRNA expression in esophageal cancer as described in other tumour types, and we wanted to generate a list of potential microRNA based biomarkers and their potential targets so that we could better understand the response to cisplatin and 5-FU based chemotherapy in esophageal cancer. By focussing on two esophageal cancer cell lines that are frequently used in other studies and are recognized to be representative of esophageal adenocarcinoma and squamous cell carcinoma (OE19 and KYSE410, respectively), we have provided preliminary data which supports the contention that miRNA expression reflects the response to chemotherapy in this cancer. Our results will require further verification, both in other esophageal cell lines and in vivo, to further evaluate this mechanism in esophageal cancer.

In addition, our current study did not include thorough target validation for all differentially expressed miRNAs. This was not one of the aims of our study, as we were primarily interested in whether the reported effect of chemotherapy on miRNA expression in other tumour types was applicable in esophageal cancer, and our study yielded a positive result. However, further investigation of the exact pathways affected by deregulation of miRNAs is the next step required for us to understand the biological consequences of altered miRNA expression and to identify those miRNAs which impact on clinical outcomes.

From our current study we can only hypothesize the impact of different chemotherapy exposure times on global miRNA expression, as the described changes in miRNA expression after 24 or $72 \mathrm{~h}$ of chemotherapy were limited by the specific selection of these miRNAs. As we did not perform a broader expression profiling by using for example microarray techniques at each time point, our findings do not allow further interpretation of the effect of short- and long-term exposure to cisplatin and 5-FU in these cell lines. However, there are so far only very limited reports about alterations in miRNA expression across different lengths of exposure to chemotherapy and the results are inconclusive $(28,29)$.

In conclusion, we have demonstrated for the first time that chemotherapy with cisplatin and 5-FU leads to changes in miRNA expression in esophageal EAC and SCC cells, and most of the identified miRNAs showed similar alterations in expression after short- vs. longer-term exposure to chemotherapy. Analysis of the predicted targets of these deregulated miRNAs suggests that these miRNAs are, in fact, impacting on functions relevant for the cellular response to a cytotoxic stimulus. These data highlight the identified miRNAs as potential candidates for clinical response monitoring of chemotherapy, and provide a basis for future studies to determine the effect of chemotherapy on the expression in vitro and in vivo. Finally, further investigations are warranted to identify the cellular pathways which are affected by the deregulated miRNAs.

\section{Acknowledgements}

Sources of funding: R.H. was supported by a Research Fellowship from the German Research Foundation DFG (Hu 1763/1-1). Funding was also obtained from a Competing Project Grant from the National Health and Medical Research Council of Australia (Grant number 595564).

\section{References}

1. Fiorica F, Di Bona D, Schepis F, Licata A, Shahied L, Venturi A Falchi AM, Craxì A and Cammà $\mathrm{C}$ : Preoperative chemoradiotherapy for oesophageal cancer: a systematic review and meta-analysis. Gut 53: 925-930, 2004. Comment in: Gut 54: 440-441, 2005.

2. Urschel JD and Vasan H: A meta-analysis of randomized controlled trials that compared neoadjuvant chemoradiation and surgery to surgery alone for resectable esophageal cancer. Am J Surg 185: 538-543, 2003.

3. Gebski V, Burmeister B, Smithers BM, Foo K, Zalcberg J and Simes J; Australasian Gastro-Intestinal Trials Group: Survival benefits from neoadjuvant chemoradiotherapy or chemotherapy in oesophageal carcinoma: a meta-analysis. Lancet Oncol 8: 226-234, 2007.

4. Schneider PM, Baldus SE, Metzger R, Kocher M, Bongartz R, Bollschweiler E, Schaefer H, Thiele J, Dienes HP, Mueller RP and Hoelscher AH: Histomorphologic tumor regression and lymph node metastases determine prognosis following neoadjuvant radiochemotherapy for esophageal cancer: implications for response classification. Ann Surg 242: 684-692, 2005. 
5. Reynolds JV, Muldoon C, Hollywood D, Ravi N, Rowley S, O'Byrne K, Kennedy J and Murphy TJ: Long-term outcomes following neoadjuvant chemoradiotherapy for esophageal cancer. Ann Surg 245: 707-716, 2007

6. Hummel R, Hussey DJ and Haier J: MicroRNAs: predictors and modifiers of chemo- and radiotherapy in different tumour types. Eur J Cancer 46: 298-311, 2010.

7. Lewis BP, Shih IH, Jones-Rhoades MW, Bartel DP and Burge CB: Prediction of mammalian microRNA targets. Cell 115: 787-798, 2003.

8. Zhang J, Zhang T, Ti X, Shi J, Wu C, Ren X and Yin H: Curcumin promotes apoptosis in A549/DDP multidrug-resistant human lung adenocarcinoma cells through an miRNA signaling pathway. Biochem Biophys Res Commun 399: 1-6, 2010.

9. Sun M, Estrov Z, Ji Y, Coombes KR, Harris DH and Kurzrock R: Curcumin (diferuloylmethane) alters the expression profiles of microRNAs in human pancreatic cancer cells. Mol Cancer Ther 7: 464-473, 2008.

10. Xia QS, Ishigaki Y, Sun L, Chen R and Motoo Y: Effect of anti-cancer drugs on the expression of BIC/miR-155 in human pancreatic cancer PANC-1 cells. Zhonghua Yi Xue Za Zhi 90: 123-127, 2010 (In Chinese).

11. Rossi L, Bonmassar E and Faraoni I: Modification of miR gene expression pattern in human colon cancer cells following exposure to 5-fluorouracil in vitro. Pharmacol Res 56: 248-253, 2007.

12. Zhao HY, Ooyama A, Yamamoto M, Ikeda R, Haraguchi M, Tabata S, Furukawa T, Che XF, Iwashita K, Oka T, Fukushima M, Nakagawa $\mathbf{M}$, Ono $\mathbf{M}$, Kuwano $\mathbf{M}$ and Akiyama S: Down regulation of c-Myc and induction of an angiogenesis inhibitor, thrombospondin-1, by 5-FU in human colon cancer KM12C cells. Cancer Lett 270: 156-163, 2008

13. Svoboda M, Izakovicova Holla L, Sefr R, Vrtkova I, Kocakova I, Tichy B and Dvorak J: Micro-RNAs miR125b and miR137 are frequently upregulated in response to capecitabine chemoradiotherapy of rectal cancer. Int J Oncol 33: 541-547, 2008.

14. Ferracin M, Zagatti B, Rizzotto L, Cavazzini F, Veronese A, Ciccone M, Saccenti E, Lupini L, Grilli A, De Angeli C, Negrini $M$ and Cuneo A: MicroRNAs involvement in fludarabine refractory chronic lymphocytic leukemia. Mol Cancer 9: $123,2010$.

15. Van der Auwera I, Limame R, van Dam P, Vermeulen PB, Dirix LY and Van Laere SJ: Integrated miRNA and mRNA expression profiling of the inflammatory breast cancer subtype. Br J Cancer 103: 532-541, 2010.

16. Ronchetti D, Lionetti M, Mosca L, Agnelli L, Andronache A, Fabris S, Deliliers GL and Neri A: An integrative genomic approach reveals coordinated expression of intronic miR-335, miR-342, and miR-561 with deregulated host genes in multiple myeloma. BMC Med Genomics 1: 37, 2008.

17. Gal H, Pandi G, Kanner AA, Ram Z, Lithwick-Yanai G Amariglio N, Rechavi G and Givol D: MIR-451 and Imatinib mesylate inhibit tumor growth of Glioblastoma stem cells. Biochem Biophys Res Commun 376: 86-90, 2008.
18. Chang KH, Mestdagh $\mathrm{P}$, Vandesompele J, Kerin MJ and Miller N: MicroRNA expression profiling to identify and validate reference genes for relative quantification in colorectal cancer. BMC Cancer 10: 173, 2010

19. Guled M, Lahti L, Lindholm PM, Salmenkivi K, Bagwan I, Nicholson AG and Knuutila S: CDKN2A, NF2, and JUN are dysregulated among other genes by miRNAs in malignant mesothelioma-A miRNA microarray analysis. Genes Chromosomes Cancer 48: 615-623, 2009.

20. Shen $Q$, Cicinnati VR, Zhang $X$, Iacob $S$, Weber $F$, Sotiropoulos GC, Radtke A, Lu M, Paul A, Gerken G and Beckebaum S: Role of microRNA-199a-5p and discoidin domain receptor 1 in human hepatocellular carcinoma invasion. Mol Cancer 9: 227, 2010.

21. Murakami Y, Yasuda T, Saigo K, Urashima T, Toyoda H, Okanoue $\mathrm{T}$ and Shimotohno $\mathrm{K}$ : Comprehensive analysis of microRNA expression patterns in hepatocellular carcinoma and non-tumorous tissues. Oncogene 25: 2537-2545, 2006.

22. Sayed D and Abdellatif M: AKT-ing via microRNA. Cell Cycle 9: 3213-3217, 2010.

23. Gonsalves CS and Kalra VK: Hypoxia-mediated expression of 5-lipoxygenase-activating protein involves HIF-1alpha and NF-kappaB and microRNAs 135a and 199a-5p. J Immunol 184: 3878-3888, 2010.

24. Ujifuku K, Mitsutake N, Takakura S, Matsuse M, Saenko V, Suzuki K, Hayashi K, Matsuo T, Kamada K, Nagata I and Yamashita S: miR-195, miR-455-3p and miR-10a(*) are implicated in acquired temozolomide resistance in glioblastoma multiforme cells. Cancer Lett 296: 241-248, 2010.

25. To KK, Robey RW, Knutsen T, Zhan Z, Ried T and Bates SE: Escape from hsa-miR-519c enables drug-resistant cells to maintain high expression of ABCG2. Mol Cancer Ther 8: 2959-2968, 2009.

26. Yu ZW, Zhong LP, Ji T, Zhang P, Chen WT and Zhang CP: MicroRNAs contribute to the chemoresistance of cisplatin in tongue squamous cell carcinoma lines. Oral Oncol 46: 317-322, 2010.

27. Zhu W, Shan X, Wang T, Shu Y and Liu P: miR-181b modulates multidrug resistance by targeting BCL2 in human cancer cell lines. Int J Cancer 127: 2520-2529, 2010.

28. Ragusa M, Majorana A, Statello L, Maugeri M, Salito L, Barbagallo D, Guglielmino MR, Duro LR, Angelica R, Caltabiano R, Biondi A, Di Vita M, Privitera G, Scalia M, Cappellani A, Vasquez E, Lanzafame S, Basile F, Di Pietro C and Purrello M: Specific alterations of microRNA transcriptome and global network structure in colorectal carcinoma after cetuximab treatment. Mol Cancer Ther 9: 3396-3409, 2010.

29. Galluzzi L, Morselli E, Vitale I, Kepp O, Senovilla L, Criollo A, Servant N, Paccard C, Hupé P, Robert T, Ripoche H, Lazar V, Harel-Bellan A, Dessen P, Barillot E and Kroemer G: miR-181a and miR-630 regulate cisplatin-induced cancer cell death. Cancer Res 70: 1793-1803, 2010. 